\title{
Multiple-Pulse Nuclear Magnetic Resonance Experiments on Some Crystalline Polymers
}

\author{
Kunihiko Fujnmoto and Toshio Nishi \\ Tokyo Research Laboratory, Bridgestone Tire Co., Ltd., \\ 2800-1, Ogawa Higashi-machi, Kodaira-shi, Tokyo 187, Japan. \\ Ryoichi KaDo \\ Department of Physics, Kyoto Industrial University, \\ Kamigamo-Motoyama, Kita-ku, Kyoto 606, Japan.
}

(Received July 30, 1971)

\begin{abstract}
The difficulties of wide line NMR or conventional pulsed NMR techniques for the analysis of heterogeneous polymer systems are discussed from the view point of principles of wide-line NMR and system recovery time of pulsed NMR. They are clarified in the case of a simple two-phase model, and the distinguishability of the two phases for both techniques is calculated. In order to overcome these difficulties the applicability of multiple-pulse NMR techniques are studied i.e., the applicability of solid echo for $T_{2}$ (spin-spin relaxation time) and of solid echo train for $T_{1}^{*}$ (spin-lattice relaxation time in rotating frame). Solid echo and solid echo train techniques are applied to Nylon 6, low-density and high-density polyethylenes. There are obtained $T_{2}$, $T_{1 \rho}^{*}$ and the fraction of the crystalline, intermediate and amorphous phases of Nylon 6 , high-density and low-density polyethylenes. In the case of low-density polyethylene, the temperature dependence of $T_{2}, T_{1 \rho}^{*}$ and the fraction of the three phases between $-120^{\circ} \mathrm{C}$ to $100^{\circ} \mathrm{C}$ are obtained.
\end{abstract}

KEY WORDS Multiple-pulse NMR / Solid Echo / Solid Echo Train / Heterogeneous Polymer Systems/Intermediate Phase/Spin-Spin Relaxation Time / Spin-Lattice Relaxation Time / Polyethylene / Nylon 6 /

The physical properties of solid or liquid polymers are greatly influenced by their morphology, dimension, volume fraction and degree of molecular motion of the structural units as well as the interaction between these units. It is known that without information about these heterogeneous structures in polymers, physical properties of polymers cannot be understood and predicted. Nuclear magnetic resonance (NMR) studies of heterogeneous polymer systems have been widely applied as one of the most effective technique which can obtain direct information about molecular motion and volume fraction of these systems. Recent broad-line NMR or pulsed NMR measurements of polyethylene $^{1}$ and poly(tetrafluoroethylene) ${ }^{2}$ indicated the possibility of the existence of an intermediate phase which is thought to be neither crystalline nor amorphus.
In order to analyse heterogeneous polymer systems by NMR the signals which are concerned with spin-lattice relaxation time $T_{1}$, spin-spin relaxation time $T_{2}$ and/or spin-lattice relaxation time $T_{1 \rho}$ in the rotating frame of each phase have to be obtained and then the relaxation time and the signal intensity of each phase calculated as indicated in Table I.

The following conditions are specially required to study heterogeneous systems.

(1) To be able to obtain continuous signals which correspond to the relaxation time of each phase in the system.

(2) The signal intensity, line shape and signalto-noise ratio should not vary according to the detecting conditions of the signal.

(3) The time required for the measurements should be short enough to be able to neglect the fluctuation during measurement of the samples 
Multiple-Pulse NMR Experiments on Some Crystalline Polymers

Table I. Several kinds of method to obtain spin-lattice relaxation time $T_{1}$ and spin-spin relaxation time $T_{2}$

\begin{tabular}{|c|c|c|}
\hline $\begin{array}{l}\text { Broad-line } \\
\text { NMR }\end{array}$ & $\begin{array}{c}T_{1} \text {, Spin-lattice relaxation time } \\
\text { Saturation method }\end{array}$ & $\begin{array}{c}T_{2} \text {, Spin-spin relaxation time } \\
\text { from NMR half width }\end{array}$ \\
\hline $\begin{array}{r}\text { Pulsed } \\
\text { NMR }\end{array}$ & $\begin{array}{l}90^{\circ}{ }_{\tau} 90^{\circ} \text { sequence } \\
180^{\circ}{ }_{\tau} 90^{\circ} \text { sequence (Null method) } \\
\text { Triplet pulse sequence } 90^{\circ}{ }_{\tau_{1}}\left(90^{\circ}{ }_{\tau_{2}} 180^{\circ}{ }_{\tau_{2}}\right. \\
\left.90^{\circ}\right)_{\tau_{1}}\left(90^{\circ}{ }_{\tau_{2}} 180^{\circ}{ }_{\tau_{2}} 90^{\circ}\right)_{\tau_{1}} \text { or } 180^{\circ}{ }_{\tau_{1}}\left(90^{\circ}{ }_{\tau_{2}}\right. \\
\left.180^{\circ}{ }_{\tau_{2}} 90^{\circ}\right)_{\tau_{1}}\left(90^{\circ}{ }_{\tau_{2}} 180^{\circ}{ }_{\tau_{2}} 90^{\circ}\right)_{\tau_{1}} \\
\text { Rotating frame } T_{1} 90^{\circ}{ }_{x} \text {, pulse of arbi- } \\
\text { trary length, shifted in phase by } \pi / 2 \\
\text { Solid echo train } T_{1 \rho}^{*} 90^{\circ}{ }_{x}{ } 90^{\circ}{ }_{y} 2 \tau 90^{\circ}{ }_{y} 2 \tau \\
90^{\circ}{ }_{y}\end{array}$ & $\begin{array}{l}\text { (a) Free induction decay after a } 90^{\circ} \text { pulse } \\
\text { (b) Spin echo after } 90^{\circ} \tau 180^{\circ} \text { pulse } \\
\text { (c) Carr \& Purcell method } 90^{\circ} \tau 180^{\circ} 2 \tau \\
180^{\circ} 2 \tau 180^{\circ} \\
\text { (d) Solid echo after } 90^{\circ}{ }_{x} \tau 90^{\circ} y \text { pulse }\end{array}$ \\
\hline
\end{tabular}

and the detecting systems.

All of the methods listed in Table $I$ do not always satisfy these conditions.

In this report, some of the difficulties in wideline NMR and conventional pulsed-NMR techniques which have been widely used to study polymer systems are clarified. To satisfy these conditions, the applicability of multiple-pulse NMR techniques are proposed, i.e., the applicability of solid echo for $T_{2}$ and solid echo train ${ }^{4}$ for $T_{1 \rho}^{*}$.

Solid eho and solid echo train techniques are applied to Nylon 6, low-density and high-density polyethylenes. It is specially attended whether one can observe the relaxation time and the fraction of the intermediate phase.

\section{POSSIBILITY OF CONVENTIONAL TECHNIQUES IN THE STUDY OF HETEROGENEOUS POLYMER SYSTEMS}

\section{Broad-Line NMR}

Let us consider the measurement of heterogeneous two phase systems from the difference in $T_{2}$ of each phase by broad-line NMR. The NMR derivative curve $F^{\prime}(H)$ will be the sum of the two derivative lines, $F_{\mathrm{a}}{ }^{\prime}(H)$ and $F_{\mathrm{b}}{ }^{\prime}(H)$ which correspond to the contributions from $\mathbf{A}$ and $\mathbf{B}$ phases, respectively, and will be expressed by eq 1 when the mole fraction and $T_{2}$ of both phases are $S_{\mathrm{a}}, S_{\mathrm{b}}$, and $T_{2 \mathrm{a}}, T_{2 \mathrm{~b}}$, respectively,

$$
\begin{aligned}
F^{\prime}(H) & =F_{\mathrm{a}}{ }^{\prime}(H)+F_{\mathrm{b}}{ }^{\prime}(H) \\
& =\left(-2 S_{\mathrm{a}} / \pi\right)\left(\left(\gamma T_{2 \mathrm{a}}\right)^{3} H\right) /\left(1+\gamma^{2} T_{2 \mathrm{a}}^{2} H^{2}\right)^{2}
\end{aligned}
$$

$$
+\left(-2 S_{\mathrm{b}} / \pi\right)\left(\left(\gamma T_{2 \mathrm{~b}}\right)^{3} H\right) /\left(1+\gamma^{2} T_{2 \mathrm{~b}}^{2} H^{2}\right)^{2}
$$

where $\gamma$ is the gyromagnetic ratio and $H$ is the excess of magnetic field from the exact resonant one. In eq 1 , the absorption line is assumed to be Lorentzian and the effect of modulation for the derivative is neglected.

Each component in the derivative curve has a minimum or a maximum where the magnetic field $H$ is equal to

$$
H_{\mathrm{a}}=1 / \sqrt{3} \gamma T_{2 \mathrm{a}}, \quad \text { or } \quad H_{\mathrm{b}}=1 / \sqrt{3} \gamma T_{2 \mathrm{~b}}
$$

Provided that the fraction of A-phase is denoted by $\beta$, and the ratio of $T_{2 \mathrm{~b}}$ to $T_{2 \mathrm{a}}$ by $\alpha$ ( $\alpha$ is greater than 1 , that is, the molecular motion in A-phase is more restrictive than that in B phase), the ratio $k$ of the maximum or minimum value of the derivative curve of A-phase to B-phase is obtained as eq 3 from eq 1 and 2 .

$$
k=F_{\mathrm{a}}{ }^{\prime}\left(H_{\mathrm{a}}\right) / F_{\mathrm{b}}{ }^{\prime}\left(H_{\mathrm{b}}\right)=\left(1 / \alpha^{2}\right)(\beta / 1-\beta),
$$

In eq $3, k$ should not be smaller than 0.1 or 0.05 in order to distinguish experimentally a signal for A-phase from that for B-phase. Therefore, there is constraint between the values of $\alpha$ and $\beta$ which one can discriminate A-phase from Bphase because of $k$ and it is obtained as

$$
\alpha \leqq \sqrt{\beta / k(1-\beta)}
$$

Curves 1 and 2 in Figure 1 illustrate eq 4 for $k=0.1$ and 0.05 , respectively.

These curves indicate that the application of broad-line NMR is less applicable to the analysis of heterogeneous systems such as low-density polyethylene with low crystallinity $(\beta=0.2, \alpha>$ 


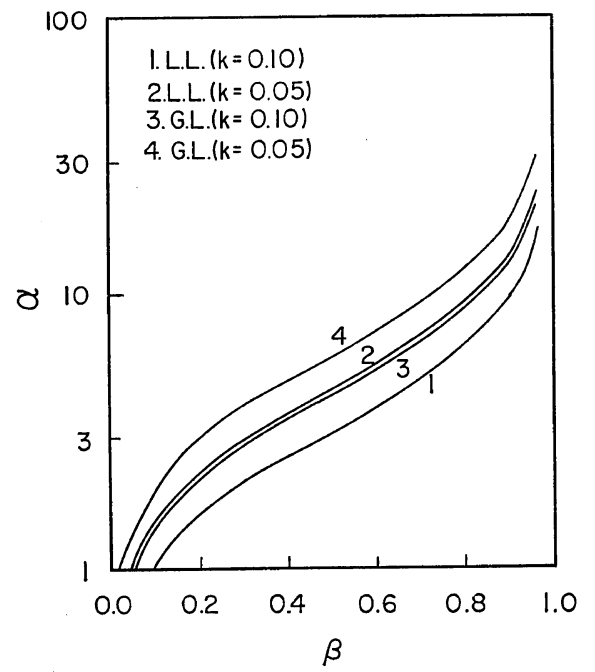

Figure 1. Constraints between the volume fraction $\beta$ of immobile phase (A) and the ratio of the $T_{2}$ of mobile phase (B) to that of the A-phase $\alpha$, when the ratio of the maximum value of the derivative curve of the signal intensity of the A-phase to that of the B-phase obtained by broad-line NMR is $k$. L. L. means that the signal shape from the both phase obtained by broad-line NMR are Lorentzian. G. L. means that that of the A-phase is Caussian and that of the B-phase is Lorentzian.

$10)$, or immobile rubber phase formed around active fillers ${ }^{10,11}(\beta \cong 0.15, \alpha>30)$. This will be indicated later in this report with experimental data.

These descriptions scarcely change if the signal shape of the A-phase is changed to Gaussian, which corresponds to assume nearly rigid lattice ${ }^{21}$ for A-phase. In this case $F_{\mathrm{a}}{ }^{\prime}(H)$ in eq 1 becomes

$$
F_{\mathrm{a}}{ }^{\prime}(H)=\left(-S_{\mathrm{a}} H / \sqrt{2 \pi}\right)\left(\gamma T_{2 \mathrm{a}}\right)^{3} \exp \left[-\left(\gamma T_{2 \mathrm{a}} H\right)^{2} / 2\right]
$$

The ratio $k$ of the maximum or minimum value of the derivative curve of A-phase to B-phase is given by

$$
\begin{aligned}
k & =F_{\mathrm{a}}{ }^{\prime}\left(H_{\mathrm{a}}\right) / F_{\mathrm{b}}{ }^{\prime}\left(H_{\mathrm{b}}\right) \\
& =\left(1 / \alpha^{2}\right)(\beta / 1-\beta)(4 / 3)(2 \pi / 3 e)^{1 / 2} \\
H_{\mathrm{a}} & =1 / \gamma T_{2 \mathrm{a}}
\end{aligned}
$$

Equation 7 holds instead of eq 4,

$$
\alpha \leqq\left((\beta / k(1-\beta))(4 / 3)(2 \pi / 3 e)^{1 / 2}\right)^{1 / 2} .
$$

Curves 3 and 4 in Figure 1 illustrate eq 7 for $k=0.1$ and 0.05 , respectively.

In the same manner when one consider the measurement of heterogeneous two-phase systems by the difference in $T_{1}$ of each phase using the saturation method of broad-line NMR and if there is no effect of spin diffusion between Aand B-phase, the observed signal will be given by the sum of the signals of the two phases under a fixed radio frequency field $H_{1}$ and is expressed by

$$
\begin{aligned}
F^{\prime}(H)= & F_{\mathrm{a}}{ }^{\prime}\left(H, H_{1}\right)+F_{\mathrm{b}}{ }^{\prime}\left(H, H_{1}\right) \\
= & {\left[-2 S_{\mathrm{a}}\left(\gamma T_{2 \mathrm{a}}\right)^{3} H_{1} / \pi\right] H /\left[1+\gamma^{2} H_{1}^{2} T_{1 \mathrm{a}} T_{2 \mathrm{a}}\right.} \\
& \left.+\left(\gamma T_{2 \mathrm{a}} H\right)^{2}\right]^{2} \\
& +\left[-2 S_{\mathrm{b}}\left(\gamma T_{2 \mathrm{~b}}\right)^{3} H_{1} / \pi\right] H /\left[1+\gamma^{2} H_{1}^{2} T_{1 \mathrm{~b}} T_{2 \mathrm{~b}}\right. \\
& \left.+\left(\gamma T_{2 \mathrm{~b}} H\right)^{2}\right]^{2}
\end{aligned}
$$

Signals from A or B-phase has a minimum or maximum when

$$
H_{\mathrm{a}}=\left(1 / \gamma T_{2 \mathrm{a}}\right)\left[\left(1+\gamma^{2} H_{1}^{2} T_{1 \mathrm{a}} T_{2 \mathrm{a}}\right) / 3\right]^{1 / 2}
$$

and

$$
H_{\mathrm{b}}=\left(1 / \gamma T_{2 \mathrm{~b}}\right)\left[\left(1+\gamma^{2} H_{1}^{2} T_{1 \mathrm{~b}} T_{2 \mathrm{~b}}\right) / 3\right]^{1 / 2}
$$

respectively.

The absolute value of the minimum or maximum has a maximum when the intensity of the applied radio frequency field $H_{1}$ is

$$
\begin{aligned}
& H_{1 \mathrm{a}}=1 /\left[\gamma\left(2 T_{1 \mathrm{a}} T_{2 \mathrm{a}}\right)^{1 / 2}\right] \text { and } \\
& H_{1 \mathrm{~b}}=1 /\left[\gamma\left(2 T_{1 \mathrm{~b}} T_{2 \mathrm{~b}}\right)^{1 / 2}\right]
\end{aligned}
$$

The maximum value of the signal of each phase is calculated by

$$
\begin{aligned}
& F_{\mathrm{a}}{ }^{\prime}\left(H_{\mathrm{a}}, H_{1 \mathrm{a}}\right)=\left(\gamma S_{\mathrm{a}} T_{2 \mathrm{a}} / 4 \pi\right)\left(T_{2 \mathrm{a}} / T_{1 \mathrm{a}}\right)^{1 / 2} \text { and } \\
& F_{\mathrm{b}}{ }^{\prime}\left(H_{\mathrm{b}}, H_{1 \mathrm{~b}}\right)=\left(\gamma S_{\mathrm{b}} T_{2 \mathrm{~b}} / 4 \pi\right)\left(T_{2 \mathrm{~b}} / T_{1 \mathrm{~b}}\right)^{1 / 2}
\end{aligned}
$$

Therefore, the ratio $k$ of the maximum in the signal of A-phase to that of B-phase is obtained by

$$
k=(\beta / 1-\beta) \alpha^{-3 / 2} \delta^{1 / 2}
$$

where

$$
\delta=T_{2 \mathrm{~b}} / T_{1 \mathrm{a}}
$$

From eq 12 there is constraint between the values of $\alpha$ and $\beta$ which one can discriminate A-phase from B-phase by saturation method and it is given as

$$
\alpha \leqq(\beta / k(1-\beta))^{2 / 3} \delta^{1 / 3}
$$




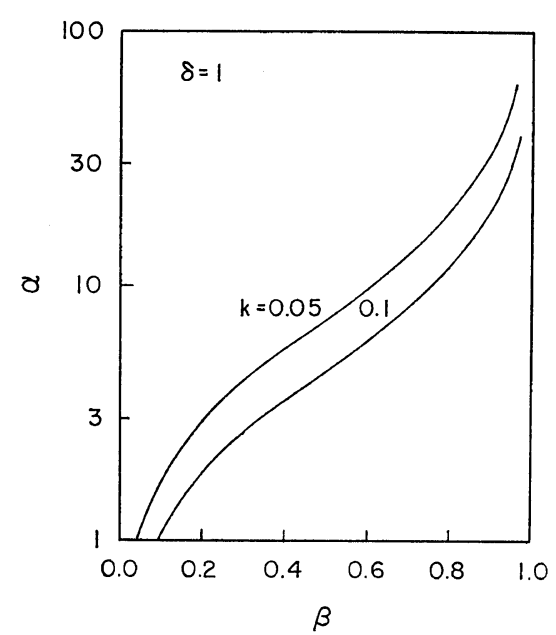

Figure 2. Constraints between the volume fraction $\beta$ of immobile phase (A) and the ratio of the $T_{2}$ of mobile phase (B) to that of the A phase $\alpha$, when the ratio of the maximum value of the derivative curve of the signal intensity of the A-phase to that of the B-phase obtained by saturation method of broad-line NMR by varying the amplitude of the applied radio frequency field $H_{1}$ is $k$. Here, the ratio of $T_{2}$ of B-phase to $T_{1}$ of A-phase $\delta$ is assumed to be 1 , since the calculated curve depends only on $1 / 3$ power of $\delta$ as eq 14 .

Figure 2 illustrates eq 14 for $k=0.1$ and 0.05 when one puts $\delta=1$ because the eq 14 depends only on cubic root of $\delta$. In this case, the constraint between the values of $\alpha$ and $\beta$ with which one can discriminate A-phase from Bphase is also very severe to the possibiltiy of observing the former phase. Moreover, the radio frequency field strength which gives the maximum values in the maximum of the derivative from A-phase and B-phase must be different each other and this condition requires

$$
H_{1 \mathrm{a}} \neq H_{1 \mathrm{~b}} \quad \text { or } \quad \alpha \neq T_{1 \mathrm{a}} / T_{1 \mathrm{~b}}
$$

These results indicate the basic difficulties in the application of broad-line NMR to the analysis of heterogeneous polymer systems. The above treatments, however, do not consider the effect of modulation in the measurement of broad-line $\mathrm{NMR}^{5-7}$ and this will be discussed in the appendix.

\section{Pulsed NMR}

Consider analysing heterogeneous systems from a free induction decay after a $90^{\circ}$ pulse. It is well known that the Fourier transform of a free induction decay after a $90^{\circ}$ pulse corresponds to ordinary NMR absorption line. ${ }^{19}$ Therefore Lorentzian and Gaussian absorption lines correspond to an exponential and a Gaussian free induction decay, respectively.

Though the observed free induction decay signal of two-phase system is given by a sum of the signals from each phase, signals cannot be observed till the system recovery time $t_{\mathrm{d}}$ just after a $90^{\circ}$ pulse. This time $t_{\mathrm{d}}$ is about 3 to $20 \mu \mathrm{sec}$ for ordinary pulsed NMR system ${ }^{8,9,21,22}$ and $t_{\mathrm{d}}$ cannot be neglected for glassy or crystalline polymers, because $T_{2}$ of these polymers ranges from 5 to $50 \mu \mathrm{sec}^{3,8,9}$

Free induction decay signal $S(t)$ after a $90^{\circ}$ pulse will be described with a Haeviside step function $H(t)$ and

$$
S(t)=H\left(t-t_{\mathrm{d}}\right)\left(S_{\mathrm{a}}(t)+S_{\mathrm{b}}(t)\right)
$$

where $S_{\mathrm{a}}(t)$ and $S_{\mathrm{b}}(t)$ correspond to signals from A-phase and B-phase, respectively.

Let the fraction of A-phase $a$ and $b$, respectively, and let the spin-spin relaxation time $T_{2}$ of A-phase and B-phase $T_{2 \mathrm{a}}$ and $T_{2 \mathrm{~b}}$, respectively. Then, $S_{\mathrm{a}}(t)$ and $S_{\mathrm{b}}(t)$ will be written by eq 17 when $S_{\mathrm{a}}(t)$ and $S_{\mathrm{b}}(t)$ have Lorentzian line shape.

$$
S_{\mathrm{a}}(t)=a \exp \left(-t / T_{2 \mathrm{a}}\right), \quad S_{\mathrm{b}}(t)=b \exp \left(-t / T_{2 \mathrm{~b}}\right)
$$

If one assumes that the molecular motion in A-phase is more restrictive than that in B-phase, the condition for detecting A-phase by a free induction decay after a $90^{\circ}$ pulse with system recovery time $t_{\mathrm{d}}$ is

$$
S_{\mathrm{a}}\left(t_{\mathrm{d}}\right) / S_{\mathrm{b}}\left(t_{\mathrm{d}}\right) \geqq k
$$

From eq 18 the constraint between the values of $\alpha$ (ratio of $T_{2 \mathrm{~b}}$ to $T_{2 \mathrm{a}}$ ) and $\beta$ (fraction of A-phase) which one can detect A-phase because of $k$ is given by

$$
\alpha \leqq 1 /(1-2.303 / s) \log [\beta / k(1-\beta)]
$$

where $s=t_{\mathrm{d}} / T_{2 \mathrm{a}}$. Figure $3 \mathrm{a}$ corrosponds to eq 19 for $k=0.05$ and 0.10 when $s=1,1 / 2$, and $1 / 4$.

Equation 19 is rewritten by eq 21 when free induction decay signal from A-phase is Gaussian as eq 20 .

$$
S_{\mathrm{a}}(t)=a \exp \left[-\left(t / T_{2 \mathrm{a}}\right)^{2} / 2\right]
$$




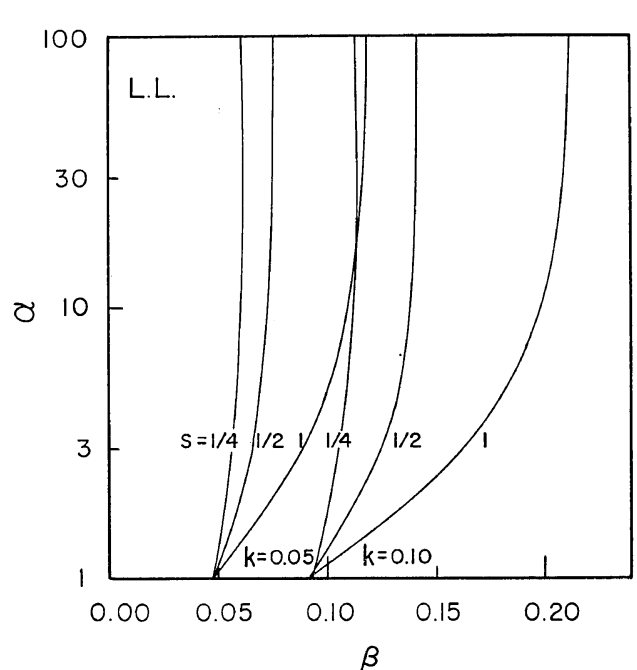

(a)

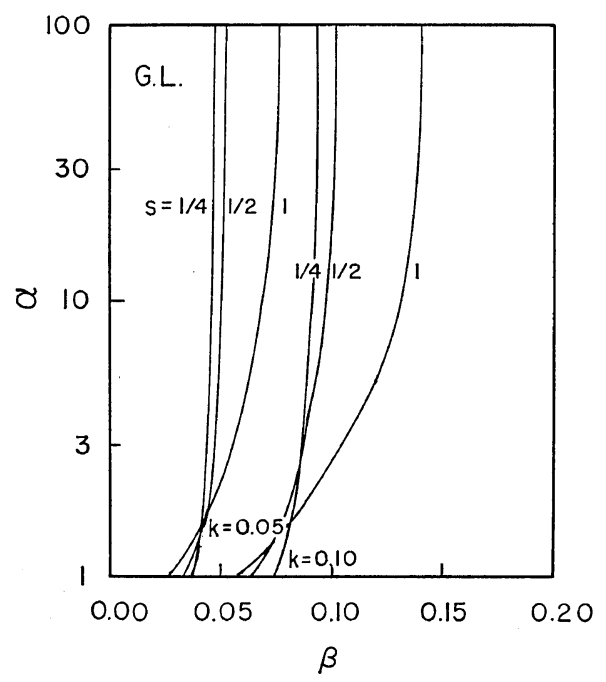

(b)

Figure 3. Constraints between the volume fraction $\beta$ of immobile phase (A) and the ratio of the $T_{2}$ of mobile phase (B) to that of the A-phase $\alpha$ when the ratio of the signal intensity of the Aphase to that of the B-phase obtained by the free induction decay after a $90^{\circ}$ pulse is $k$ at time $t_{\mathrm{d}}$. Here, $t_{\mathrm{d}}$ means the system recovery time after a $90^{\circ}$ pulse and $\mathrm{s}$ means the ratio of $t_{\mathrm{d}}$ to the spinspin relaxation time of the A-phase $T_{2 \mathrm{a}}$. (a) the shape of both signal is assumed to be Lorentzian. (b) the shape of the signal from the A-phase is assumed to be Gaussian and that of the B-phase is assumed to be Lorentzian.

$$
\alpha=1 /(s / 2-2.303 / s) \log [\beta / k(1-\beta)]
$$

Figure $3 \mathrm{~b}$ corresponds to eq 21 for $k=0.05$ and 0.10 when $s=1,1 / 2$, and $1 / 4$.

It is quite evident from Figures 1 to 3 that pulsed NMR is more useful than broad-line NMR for the analysis of heterogeneous polymer systems, but even the pulsed NMR is not sufficient to detect a small quantity of immobile fraction in a mobile matrix for the system recovery time $t_{\mathrm{d}}$ after a pulse. It is not impossible to analyse heterogeneous polymer systems by $T_{1}, T_{2}$ and/or $T_{1 \rho}$ using $90^{\circ} \tau 90^{\circ}$ or $180^{\circ} \tau 90^{\circ}$, $90^{\circ} \tau 180^{\circ}$ and/or rotating frame $T_{1 \rho}$ method, but in all cases one has to vary $\tau$ stepwise. Consequently, the data cannot be obtained continuously and may be influenced by the fluctuation of the sample and the NMR system during the measurement. Carr and Purcells method for $T_{2}$ is also not convenient for them since in solids the $T_{2}$ is not always much longer than $\tau$ in order to make multiple spin echoes.

\section{Applicability of Multiple-Pulse NMR}

It has been clarified that a broad-line NMR or an ordinary-pulsed NMR technique has difficulties originated from its principle or system recovery time and they cannot fulfill the three conditions mentioned in the introduction for the analysis of heterogeneous polymer systems. The authors propose in the following the applicability of multiple-pulse NMR.

To analyse from $T_{2}$, the solid echo technique ${ }^{3}$ can effectively diminish the influence of the system recovery time by moderately choosing $\tau$. To analyse them from $T_{1 \rho}$, one can measure $T_{1 \rho}^{* 4}$ also at the same time by applying the solid echo train sequence. Applicability of these multiple-pulse NMR techniques for the analysis of heterogeneous polymer systems has not yet been confirmed and it is also desired that detailed information described in the introduction may be obtained by them.

Nylon 6, high-density and low-density polyethylenes are used to confirm the existence of the intermediate phase, considered to be neither crystalline nor amorphous phase by applying solid echo and solid echo train. In the case of low-density polyethylene, temperature dependence of the fraction, $T_{2}$ and $T_{1 o}^{*}$ of each phase has been measured between $-110^{\circ} \mathrm{C}$ and $100^{\circ} \mathrm{C}$. 


\section{Samples}

Some physical properties of polyethylenes and Nylon 6 used in this study are listed in Table II. Four kinds of polyethylene were used.

Table II. Physical properties of high-density polyethylene (HDPE), low-density polyethylene (LDPE), and Nylon 6

\begin{tabular}{lccccc}
\hline & $d^{\mathrm{a}}$ & $\begin{array}{c}\alpha_{\mathrm{d}},{ }^{\mathrm{b}} \\
\%\end{array}$ & $\begin{array}{c}\mathrm{mp},{ }^{\mathrm{c}} \\
{ }^{\mathrm{C}}\end{array}$ & $\begin{array}{c}\Delta H,{ }^{\mathrm{d}} \\
\mathrm{cal} / \mathrm{g}\end{array}$ & $\begin{array}{c}\alpha_{\Delta H},{ }^{\mathrm{e}} \\
\%\end{array}$ \\
\hline HDPE (6050X) & 0.9905 & 93.7 & $\begin{array}{c}136.0 \\
(128.5)\end{array}$ & 60.0 & 37 \\
HDPE (6050) & 0.9665 & 79.1 & 128.9 & 40.7 & 58.8 \\
LDPE (B) & 0.9238 & 51.1 & 110.9 & 17.8 & 25.1 \\
LDPE (A) & 0.9160 & 45.6 & 101.3 & 11.4 & 16.5 \\
Nylon 6 & 1.1589 & 49.8 & 219.7 & 18.3 & 40.7 \\
\hline
\end{tabular}

${ }^{a} d$, density. ${ }^{\mathrm{b}} \alpha_{\mathrm{d}}$, degree of crystallinity calculated from $d$. ' $\mathrm{mp}$, melting point. a $\Delta H$, heat of fusion. ${ }^{e} \alpha_{\Delta H}$, degree of crystallinity calculated from $\Delta H$.

HDPE $(6050 \mathrm{X})$ was prepared by annealing highdensity polyethylene (6050) from the melt and crystallizing it at $126.5^{\circ} \mathrm{C}$ for 50 hours, it had a high degree of crystallinity. On the other hand, HDPE (6050) was obtained by quenching high-density polyethylene from the melt, and had a lower degree of crystallinity than HDPE $(6050 \mathrm{X})$. Low-density polyethylene LDPE (A) and LDPE (B) had different degree of crystallinity.

In Table II, $d$ means the density of the sample measured by density gradient tube at $25^{\circ} \mathrm{C}$, and $\alpha_{\mathrm{d}}$ means the degree of crystallinity calculated from eq 22 .

$$
\alpha_{\mathrm{d}}=\left[d_{\mathrm{c}} /\left(\boldsymbol{d}_{\mathrm{c}}-\boldsymbol{d}_{\mathrm{a}}\right)\right]\left(d-d_{\mathrm{a}}\right) / d
$$

where $d_{\mathrm{a}}$ is the density of the amorphous state of the sample and it is $0.855 \mathrm{~g} / \mathrm{cm}^{3}$ for polyethylene $^{12}$ and $1.10 \mathrm{~g} / \mathrm{cm}^{3}$ for Nylon $6{ }^{13}$ The quantity $d_{\mathrm{c}}$ is the density of the crystalline state of the sample and it is $1.001 \mathrm{~g} / \mathrm{cm}^{3}$ for polyethylene ${ }^{12}$ and $1.23 \mathrm{~g} / \mathrm{cm}^{3}$ for Nylon $6{ }^{13}$

Melting point $\mathrm{mp}\left({ }^{\circ} \mathrm{C}\right)$ and heat of fusion $\Delta h$ $(\mathrm{cal} / \mathrm{g})$ are measured by differential scanning calorimeter (DSC) type DSC-I manufactured by Perkin-Elmer Co. Temperature and heat of fusion are calibrated with pure benzoic acid $\left(\mathrm{mp} 121^{\circ} \mathrm{C}, \Delta h=33.93 \mathrm{cal} / \mathrm{g}\right)$ and tin $\left(\mathrm{mp} 232^{\circ} \mathrm{C}\right.$, $\Delta h=14.2 \mathrm{cal} / \mathrm{g}$ ) as standard samples.
Degree of crystallinity from the heat of fusion of the sample $\alpha_{\lrcorner h}$ was calculated using that of the crystalline state of the sample as $69.2 \mathrm{cal} / \mathrm{g}$ for polyethylene $e^{14}$ and $45 \mathrm{cal} / \mathrm{g}$ for Nylon $6 .^{15}$

\section{METHOD OF MEASUREMENT AND ANALYSIS OF THE DATA}

\section{Solid Echo after $90^{\circ}{ }_{x} \tau 90^{\circ}$ Pulse}

Solid echo was obtained $\tau$ seconds after a $90^{\circ} \tau 90^{\circ}{ }_{y}$ pulse, where $90^{\circ}{ }_{x}$ and $90^{\circ}{ }_{y}$ pulse mean a $90^{\circ}$ pulse whose direction is to the $x$ and $y$ axis in the rotating frame, respectively. According to Powles and Strange ${ }^{3}$ NMR transients $\tau$ seconds after the second pulse can be a good approximation to a free induction decay after a $90^{\circ}$ pulse.

Adjusting $\tau$ as

$$
\text { Min. }\left(T_{2}\right)>\tau \geqq t_{\mathrm{d}}
$$

one can observe the equivalent whole shape of the free induction decay after a $90^{\circ}$ pulse from heterogeneous polymer systems without influence of the system recovery time.

The solid echo of each sample was observed at a resonance frequency of $55 \mathrm{MHz}$ by setting $\tau=6 \mu \mathrm{sec}$ and the pulse duration $t_{\mathrm{w}}=4 \mu \mathrm{sec}$ (which corresponds to the intensity of the pulse $H_{1}$ being about 15 Oersted) since the shortest $T_{2}$ of the heterogeneous polymer systems is about 8 to $10 \mu \mathrm{sec}$ even if it is from polymer crystals. ${ }^{8,9}$ In this case, the system recovery time was about $4 \mu \mathrm{sec}$. The pulsed NMR system used is a type PS-60 A manufactured by the NMR Specialties Co..

\section{Solid Echo Train $T_{1 \rho}^{*}$}

According to Waugh and Wang, ${ }^{4}$ the solid echo train can be obtained by applying $90^{\circ}{ }_{x} \tau$ $90^{\circ}{ }_{y} 2 \tau \quad 90^{\circ}{ }_{y} 2 \tau \quad 90^{\circ} \quad 2 \tau \ldots$ pulse train to the spin system in the rotating frame. This situation seems to be almost equivalent to "spin locking" to the $y$-axis of the rotating frame and the envelope of the solid echo train $S(t)$ is shown to decrease according to

$$
S(t)=S_{0} \exp \left(-t / T_{1 \rho}^{*}\right)
$$

They have also proved both theoretically and experimentally that $T_{1 \rho}^{*}$ in eq 24 approaches the spin-lattice relaxation time $T_{1 \rho}$ in the rotating frame when $\tau$ decreases, 


$$
\lim _{\tau \rightarrow 0} T_{1 \rho}^{*}=T_{1 \rho}
$$

In this case, however, the following condition must be fulfilled.

$$
\omega_{0}^{-1} \ll \tau_{\mathrm{c}} \ll \omega_{1}^{-1} \sim \tau \ll T_{2} \ll T_{1}
$$

where $\omega_{0}$ is the resonant angular frequency of the spin, and $\tau_{\mathrm{c}}$ is the correlation time of the fluctuating local magnetic field, and $\omega_{1}$ corresponds to the angular frequency of the applied pulse (i.e., $\gamma H_{1}$ ).

In our experiment $\tau$ has been adjusted as $6 \mu \mathrm{sec}$ and the pulse width as $4 \mu \mathrm{sec}$ and the repeating of the applied pulse has been 500 to 2000. For polyethylene and Nylon 6, these exp-

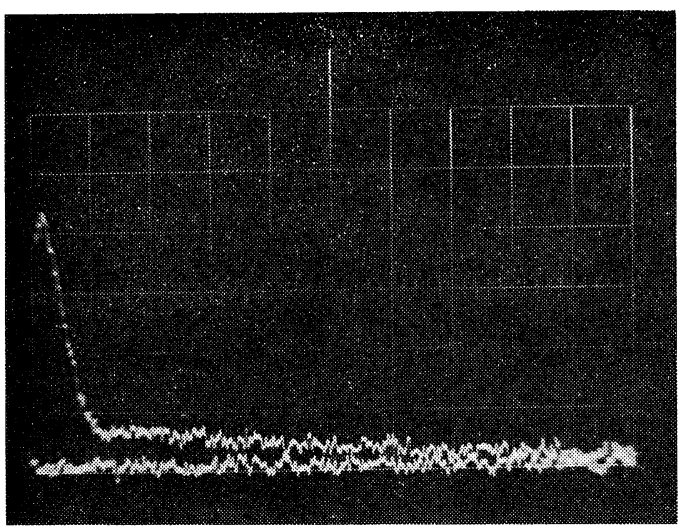

(a)

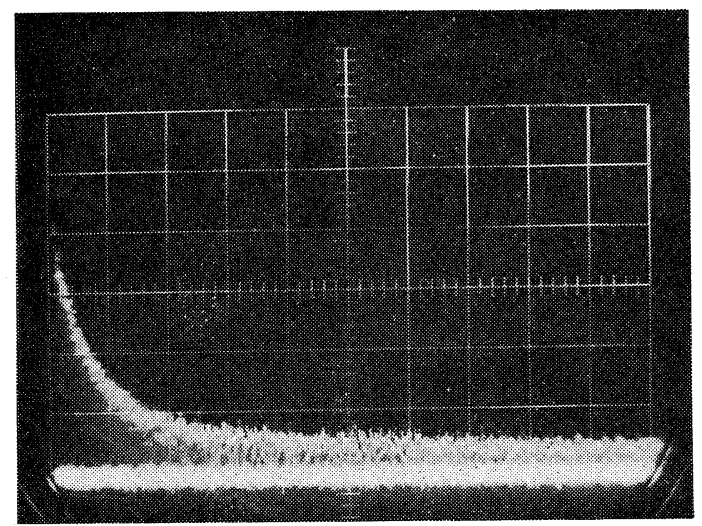

(c) erimental conditions satisfy eq 26 , since the following may be assumed.

$$
\begin{aligned}
T_{2}>7 \mu \mathrm{sec}, T_{2} \ll T_{1} \sim 1 \mathrm{sec}, \\
\omega_{0}^{-1}=2.9 \mathrm{nsec}, \omega_{1}^{-1}=2.5 \mu \mathrm{sec}
\end{aligned}
$$

Therefore, the solid echo train method is quite advantageous to analyse heterogeneous polymer systems, for one can measure the $T_{1 \rho}$ of the system by a single measurement.

The sample temperature was regulated to $\pm 0.5^{\circ} \mathrm{C}$ by a stream of heated or cooled nitrogen gas. The temperature was monitored by a copper-constantan thermocouple placed near the sample tube. Samples $c a .1 .5 \mathrm{~cm}^{3}$ in volume

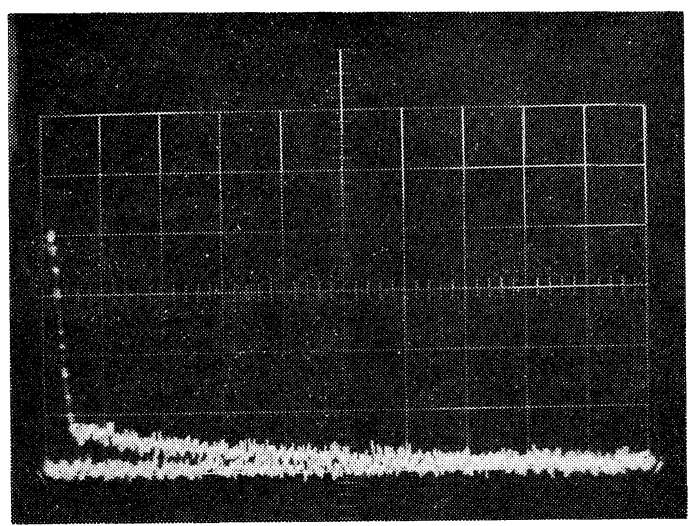

(b)

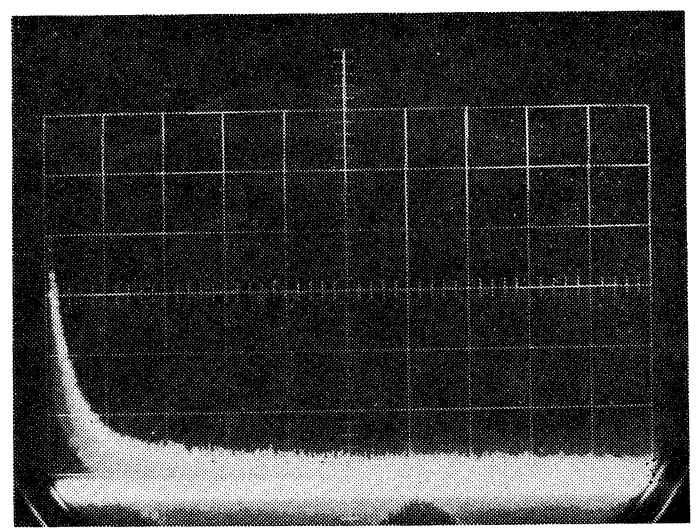

(d)

Figure 4. Solid echo and solid echo train signals from high-density polyethylene at $120^{\circ} \mathrm{C}$ (HDPE $6050 \mathrm{X}$ ): (a) solid echo decay, H, $20 \mu \mathrm{s} / \mathrm{unit}$; (b) solid echo decay, $\mathrm{H}, 50 \mu \mathrm{s} / \mathrm{unit}$; (c) solid echo train, $\mathrm{H}, 500 \mu \mathrm{s} /$ unit $\tau=6 \mu \mathrm{s}$; (d) solid echo train, $\mathrm{H}, 1 \mathrm{~ms} / \mathrm{unit} \tau=6 \mu \mathrm{s}$; resonance frequency, $55 \mathrm{MHz}$; pulse duration, $4 \mu \mathrm{s}$; pulse height, 15 gauss. 
were randomly packed in glass tubing whose inner diameter was $8 \mathrm{~mm}$.

\section{Analysis of the Data}

Solid echo or solid echo train of each sample displayed on the synchroscope were photographed using a Polaroid Camera. At the same time the time axis was photographed since the relative intensity of the signal is important to analyse heterogeneous systems.

Signal intensity of the photograph has been digitized and printed out using the oscillogram tracer manufactured by the Eto Electric Co., Ltd.. The signal intensity at time $t=0$ was set to 1000 and the time axis was proceeded automatically by fixed step.

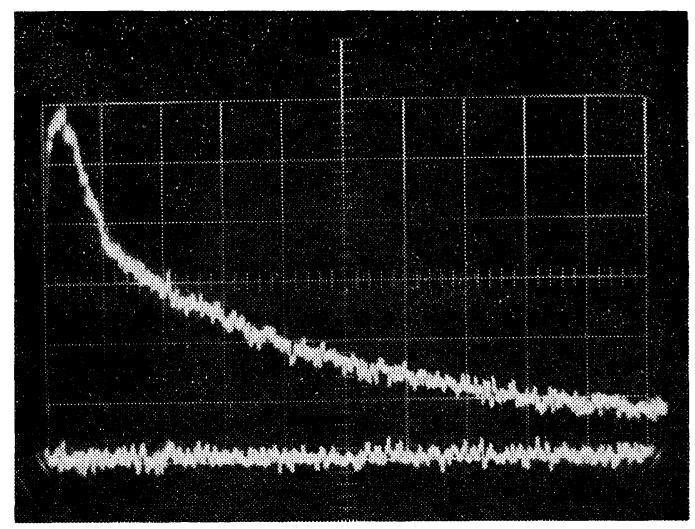

(a)

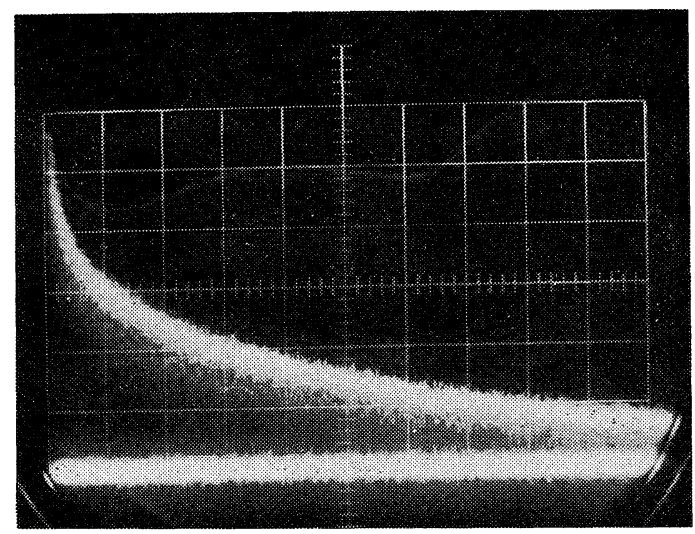

(c)
Solid echo from heterogeneous system is composed of many signals which correspond to many phases with different correlation time $\tau_{\mathrm{c}}$ or different degree of distribution in $\tau_{\mathrm{c}}$. In this analysis, it has been assumed that the signal corresponding to short $\tau_{\mathrm{c}}$ as in rubbery or liquid-like phase decreases as $\exp \left(-t / T_{2}\right),{ }^{23}$ and the signal corresponding to long $\tau_{\mathrm{c}}$ as in glassy or crystalline phase decerases as $\exp \left[(-1 / 2)\left(t / T_{2}\right)^{2}\right]$. Actually the NMR line shape in crystalline phase is not Gaussian especially at low temperatures where molecular motion is frozen and it will be indicated later. However, at relatively high temperatures where one can see the heterogeneous components, it is found relevant to assume

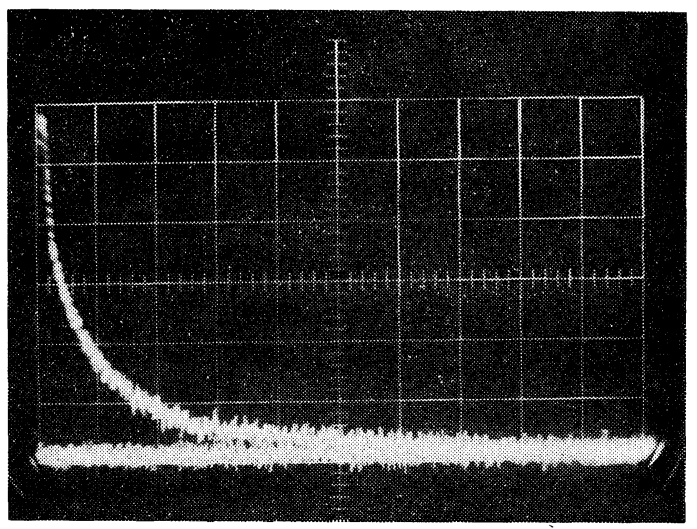

(b)

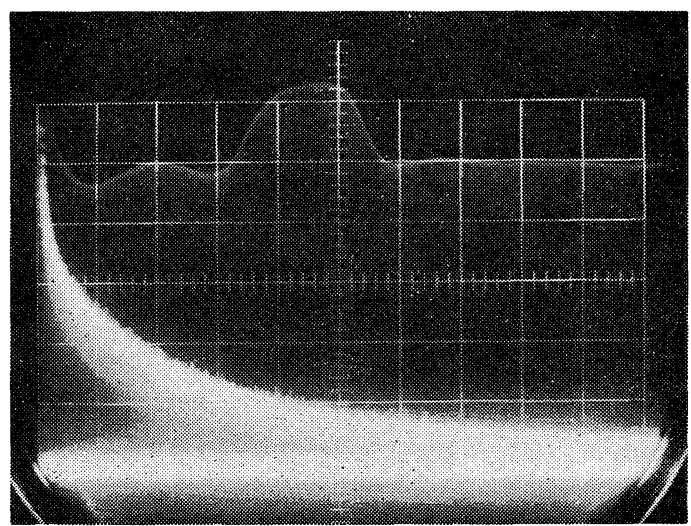

(d)

Figure 5. Solid echo and solid echo train signals from low-density polyethylene at $80^{\circ} \mathrm{C}$ (LDPE A): (a) solid echo decay, H, $20 \mu \mathrm{s} / \mathrm{unit}$; (b) solid echo decay, H, $100 \mu \mathrm{s} / \mathrm{unit}$; (c) solid echo train, H, $1 \mathrm{~ms} /$ unit $\tau=6 \mu \mathrm{s}$; (d) solid echo train, $\mathrm{H}, 2 \mathrm{~ms} /$ unit $\tau=6 \mu \mathrm{s}$; resonance frequency, $55 \mathrm{MHz}$; pulse duration, $4 \mu \mathrm{s}$; pulse height, 15 gauss. 
Gaussian decay. This phenomenon may correspond to the decrease in the second moment of NMR absorption line observed in crystalline polymers because of the active molecular motion in the crystalline phase. ${ }^{25}$ Consequently, the data have been analysed by plotting the data in a $\log S \sim t$ chart and then subtracting the signal that has the longest $T_{2}$ and replotting the data, and then subtracting the signal that has the longest $T_{2}$ in the replotted chart and so on.

The envelope of the solid echo train has also been analysed as just the same ways as in the case of the analysis of the solid echo. But, in this case, the decrease of the signal from each phase has been assumed as $\exp \left(-t / T_{1 \rho}^{*}\right)$.

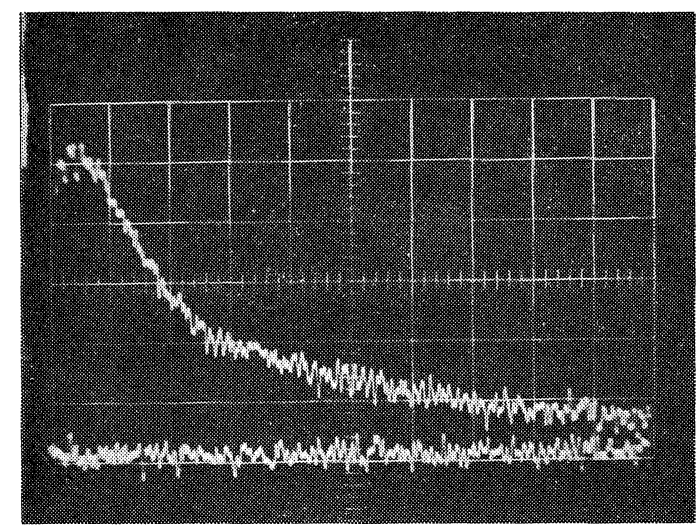

(a)

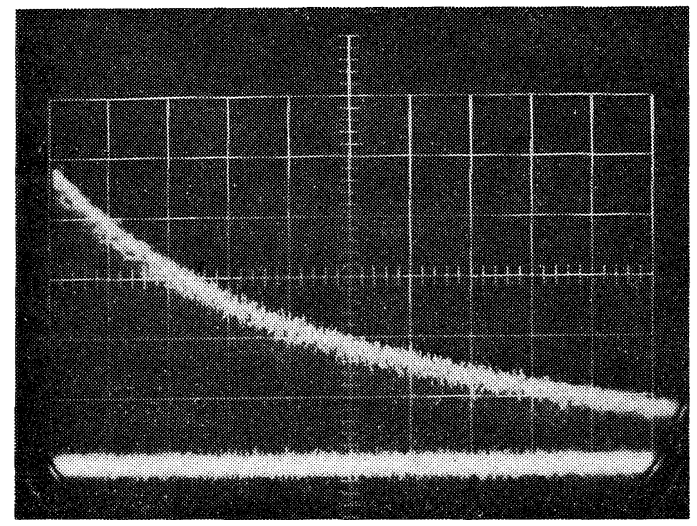

(c)
In both cases the fraction of each phase is estimated from the value of intersection of the $s$-axis at $t=0$.

\section{RESULTS AND DISCUSSION}

Examples of photographs of the solid echo and the solid echo train from high-density polyethylene HDPE $(6050 \mathrm{X})$ at $120^{\circ} \mathrm{C}$, low-density polyethylene LDPE (A) at $80^{\circ} \mathrm{C}$ and Nylon 6 at $150^{\circ} \mathrm{C}$ are presented as Figures 4,5 , and 6 , respectively. Each sample is measured at relatively higher temperature since the difference in correlation time of local magnetic field in heterogeneous system will become pronounced

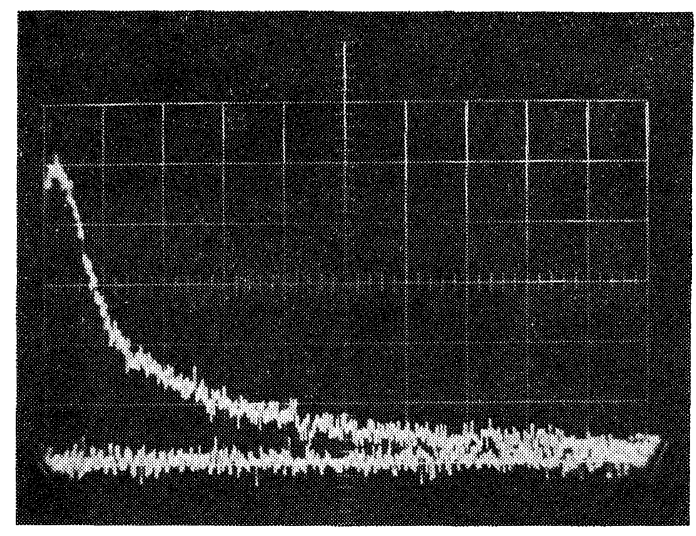

(b)

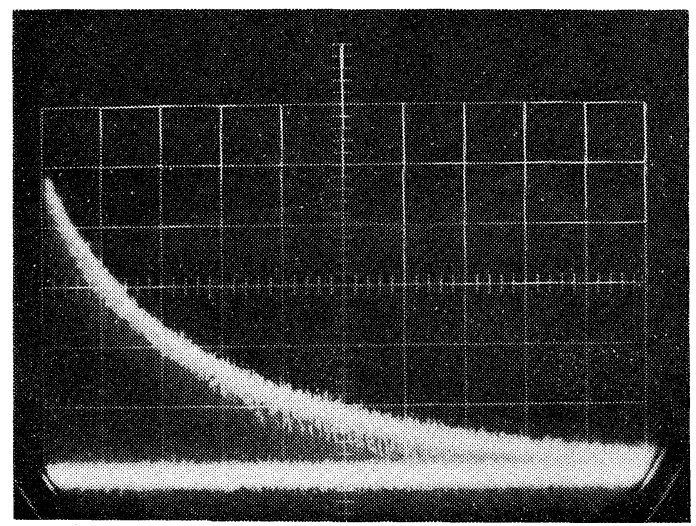

(d)

Figure 6. Solid echo and solid echo train signals from Nylon 6 at $150^{\circ} \mathrm{C}$ : (a) solid echo decay, $\mathrm{H}, 10 \mu \mathrm{s} / \mathrm{unit}$; (b) soild echo decay, H, $20 \mu \mathrm{s} / \mathrm{unit}$; (c) solid echo train, $\mathrm{H}, 500 \mu \mathrm{s} / \mathrm{unit} \tau=6 \mu \mathrm{s}$; (d) solid echo train, $\mathrm{H}, 1 \mathrm{~ms} / \mathrm{unit} \tau=6 \mu \mathrm{s}$; resonance frequency, $55 \mathrm{MHz}$; pulse duration, $4 \mu \mathrm{s}$; pulse height, 15 gauss. 
Multiple-Pulse NMR Experiments on Some Crystalline Polymers

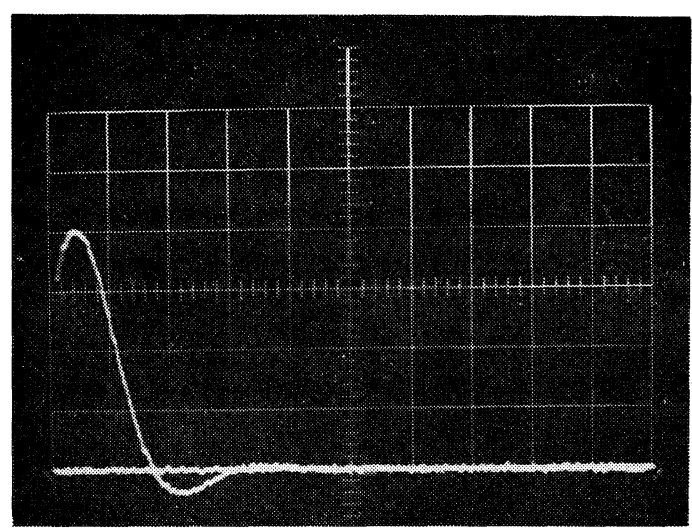

(a)

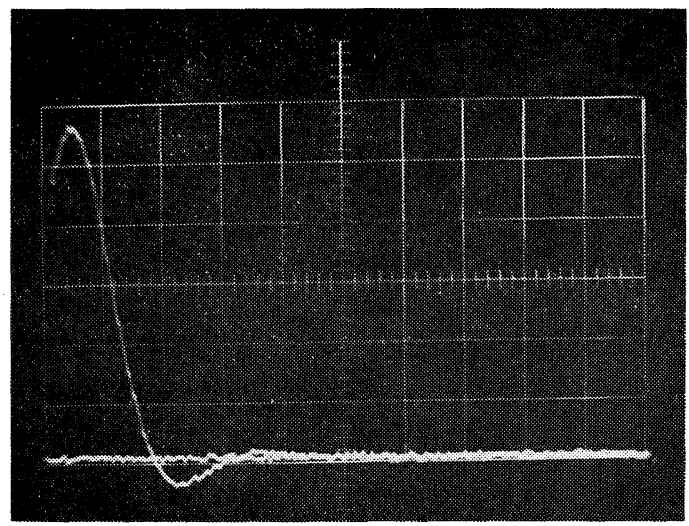

(c)

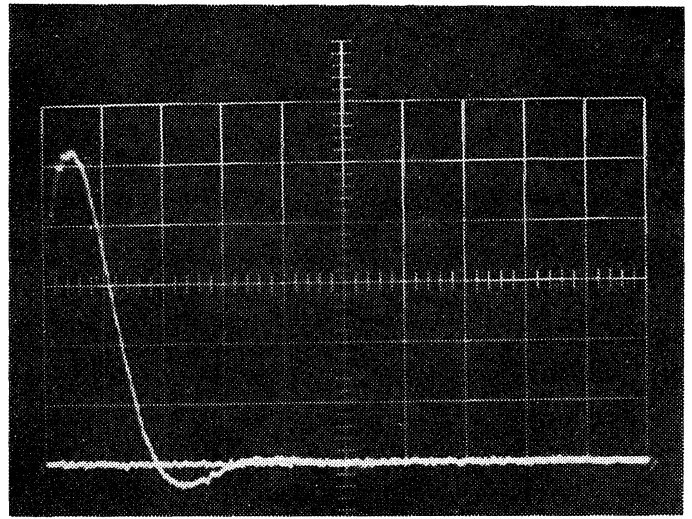

(b)

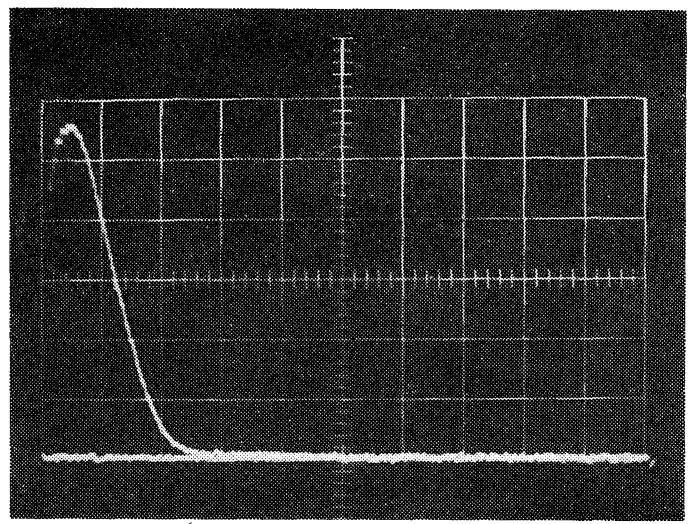

(d)

Figure 7. Solid echo signals from several samples at liquid $\mathrm{N}_{2}$ temperature: $\mathrm{H}, 10 \mu \mathrm{s} / \mathrm{unit}$; (a) HDPE (6050 X); (b) LDPE (A); (c) Nylon 6; (d) NR vulcanizate.

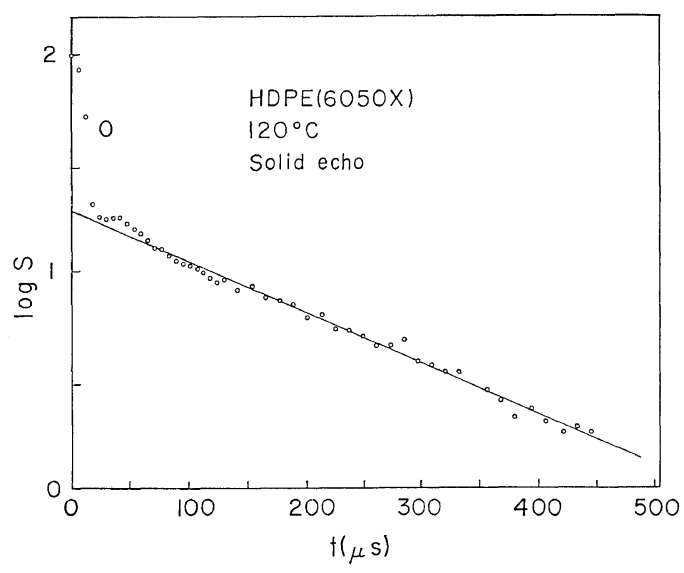

(a)

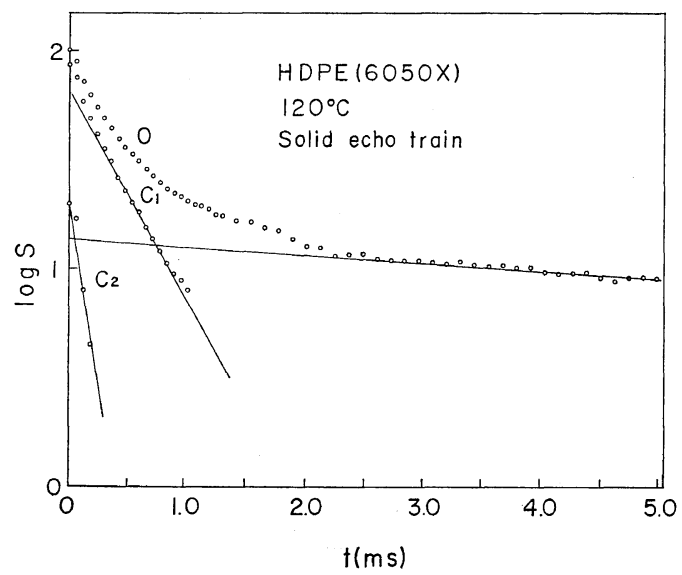

(b)

Figure 8. Analysis of the Figure 4 of high-density polyethylene. 
when the amorphous phase of the system is at least above its glass-transition temperature. Under these conditions it will be easier to distinguish between crystalline, amorphous and intermediate phases in the system.

Figure 7 indicates the solid echo of each sample at liquid $\mathrm{N}_{2}$ temperature far below the glass-transition temperature and there are not signals that correspond to amorphous or intermediate phase. Beats appear in the solid echo of polyethylene or Nylon 6. This phenomenon shows that the absorption curve given by Fourier transform of the signal is not Gaussian but rather bell-shaped.

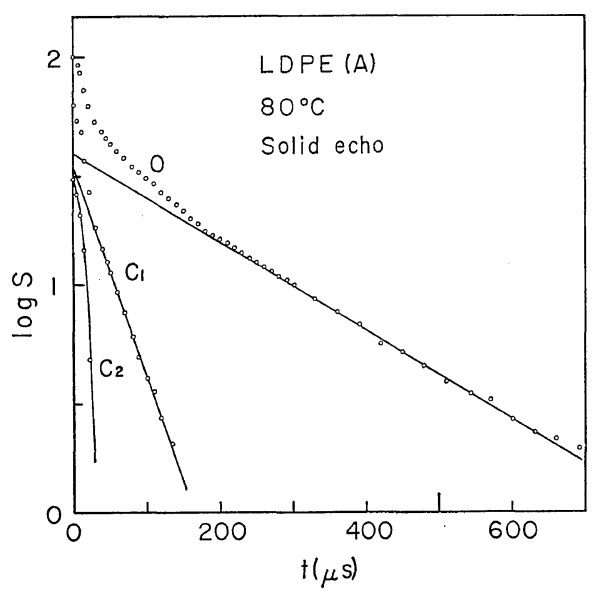

(a)

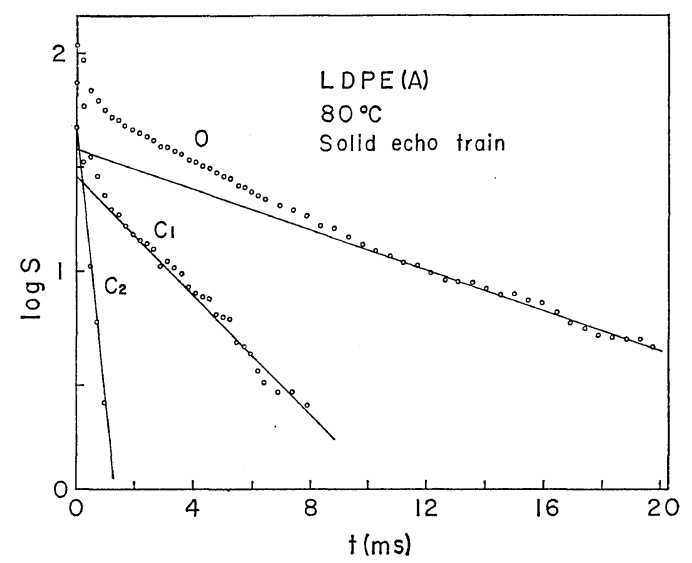

(c)
Examples of the results of the analysis of the Figures 4, 5, and 6 are given in Figures 8(a), (b), 9(a), (b), (c), (d), and 10(a), (b). Symbol O corresponds to the plot of the digitized data obtained from the photos and symbol $\mathrm{C}_{1}$ corresponds to the result of the subtraction of the signal having the longest $T_{2}$ or $T_{1 \rho}^{*}$ from the curve designated by the symbol $\mathrm{O}$. Symbol $\mathrm{C}_{2}$ corresponds to the result of the subtraction of the signal having the longest $T_{2}$ or $T_{1 \rho}^{*}$ in the curve $C_{1}$ from the curve $C_{1}$.

In many cases there clearly exist three phases. It is concluded from the analysis of the solid echo the signal having the shortest $T_{2}$ decays as a

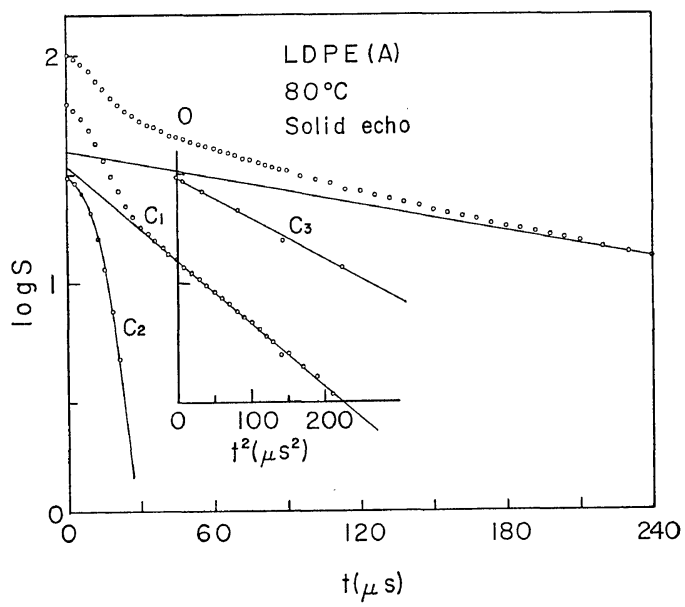

(b)

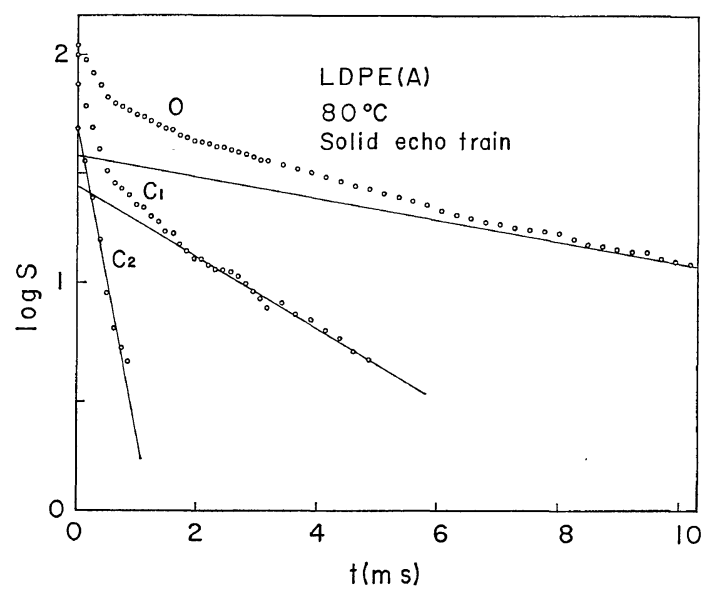

(d)

Figure 9. Analysis of the Figure 5 of low-density polyethylene. 
Multiple-Pulse NMR Experiments on Some Crystalline Polymers

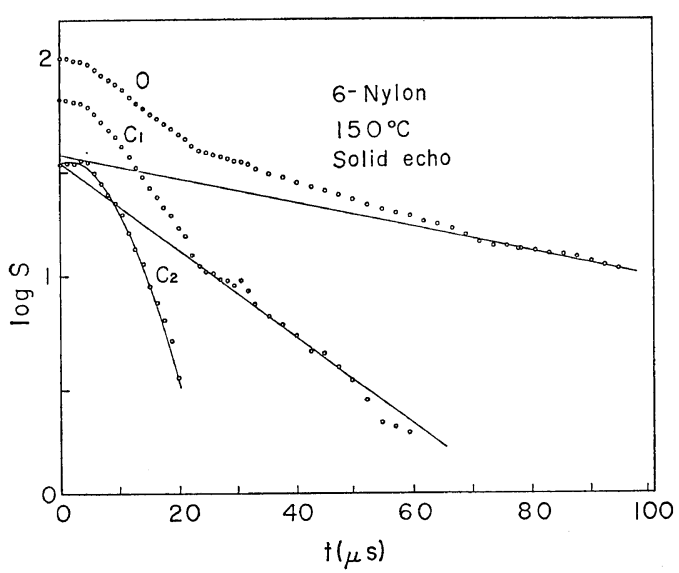

(a)

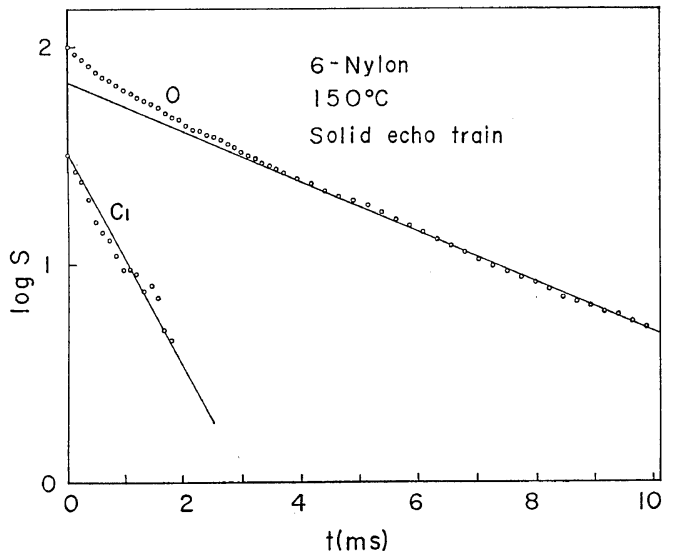

(b)

Figure 10. Analysis of the Figure 6 of Nylon 6.

Gaussian function and may be ascribed to the crystalline phase of the sample (Figures 8(a), 9(a), (b), and 10(a)), and the other signals having intermediate and the longest $T_{2}$ decay as an exponential function and may be ascribed to those from intermediate and amorphous phase of the sample. The amorphous and intermediate phase in polyethylene might correspond to two $T_{1}{ }^{\prime} \mathrm{s}$ found in the amorphous phase by Peterlin, et al. ${ }^{21}$ The intermediate phase in Nylon 6 might correspond to one found in even number polyamides by Takayanagi $^{20}$ but it cannot be concluded so since the data for odd number polyamides have not been obtained.

The fraction, $T_{2}$ and $T_{1 \rho}^{*}$ of each phase are calculated and listed in Table III. The reasons
Table III. Volume fraction, $T_{2}$ and $T_{1 \rho}^{*}$ of the three phases of LDPE (A), HDPE (6050 X) and Nylon 6 from Figures 8 to 10

\begin{tabular}{clrrrrr}
\hline & \multicolumn{3}{c}{$T_{2}$} & & \multicolumn{3}{c}{$T_{1 \rho}^{*}$} \\
\hline LDPE (A) & $29 \%$ & 32 & 39 & 47 & 27 & 36 \\
$80^{\circ} \mathrm{C}$ & $11 \mu \mathrm{s}$ & 48 & 220 & 460 & 3300 & 12000 \\
HDPE $(6050 \mathrm{X})$ & $81 \%$ & 19 & & 20 & 66 & 14 \\
$120^{\circ} \mathrm{C}$ & $7.5 \mu \mathrm{s}$ & 185 & & 130 & 450 & 10700 \\
Nylon-6 & $31 \%$ & 33 & 36 & 26 & 74 & \\
$150^{\circ} \mathrm{C}$ & $7.0 \mu \mathrm{s}$ & 22 & 77 & 770 & 3700 &
\end{tabular}

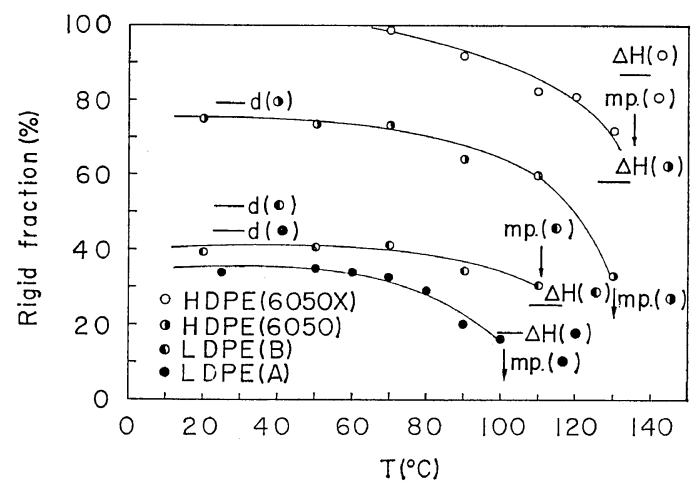

Figure 11. Temperature dependence of the rigid fraction of polyethylenes calculated from the solid echo signals of them.

for the disagreement of the fraction between each phase calculated from the $T_{2}$ decided by solid echo and $T_{1 \rho}^{*}$ decided by solid echo train are thought to be the affection of spin diffusion ${ }^{24}$ between crystalline and intermediate or amorphous phase in the $T_{1 \rho}^{*}$ measuremets. Heterogeneous polymers can be analysed easily by solid echo in this respect.

Figure 11 shows the temperature dependence of the rigid fraction (or the dynamical degree of crystallinity ${ }^{17}$ ) of polyethyene from the solid echo of each sample. Symbol d(O) designates the degree of crystallinity calculated from the density of each sample and symbols $m p(O)$ and $\Delta \mathrm{H}(\mathrm{O})$ the melting point and the degree of crystallinity calculated from the heat of fusion of each sample.

The rigid fraction obtained from NMR lies intermediate between the degree of crystallinity calculated from the density and the heat of fusion of the sample. The temperature dependence of the rigid fraction is less sensitive to 
temperature than that obtained by broad-line NMR. ${ }^{25}$ This might suggest that the data of heterogeneous polymer systems obtained by broadline NMR are greatly influenced by the modulation effect of the signal and even if the degree of crystallinity do not change with temperature, the relative intensity of the narrow component increases when the width of the narrow component decreases in higher temperatures. Consequently, the rigid fraction or the dynamical degree of crystallinity decreases rapidly with temperature. This situation will be clarified in the appendix.

It can be concluded that the existence of crystalline, amorphous and intermediate phases in polyethylene and Nylon 6 is proved. As a typical example of them, the temperature dependence of the fraction, $T_{2}$ and $T_{1, o}^{*}$ of each phase of the low-density polyethylene LDPE (A) is measured also by the solid echo and the solid echo train between -120 to $110^{\circ} \mathrm{C}$. Figures 12,13 , and 14 illustrate the temperature dependence of $T_{2}, T_{1 \rho}^{*}$, and the fraction of the each phase. It is clear from Figures 12 and 14 that the amorphous phase of the system has glass transition above about $-40^{\circ} \mathrm{C}$ and the intermediate phase begins to be observed separately from the others above about $20^{\circ} \mathrm{C}$. From the data of the solid echo train siganls one can obtain the

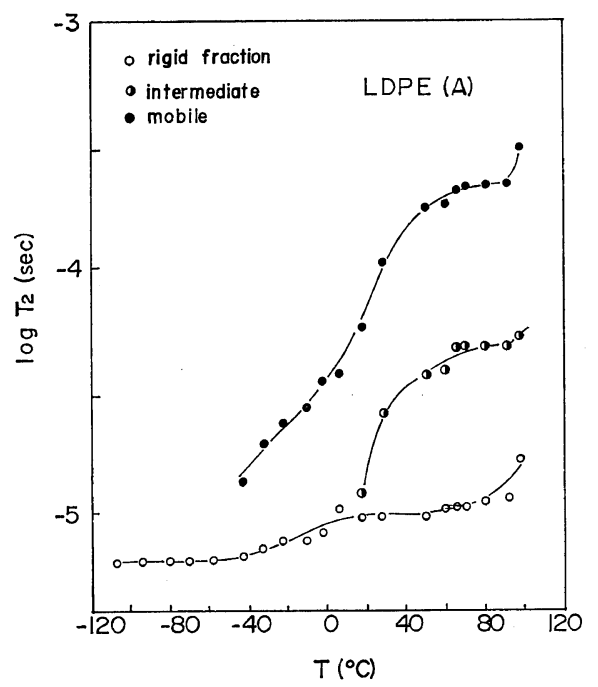

Figure 12. Temperature dependence of $T_{2}$ of the three phases in LDPE (A) obtained by solid echo.

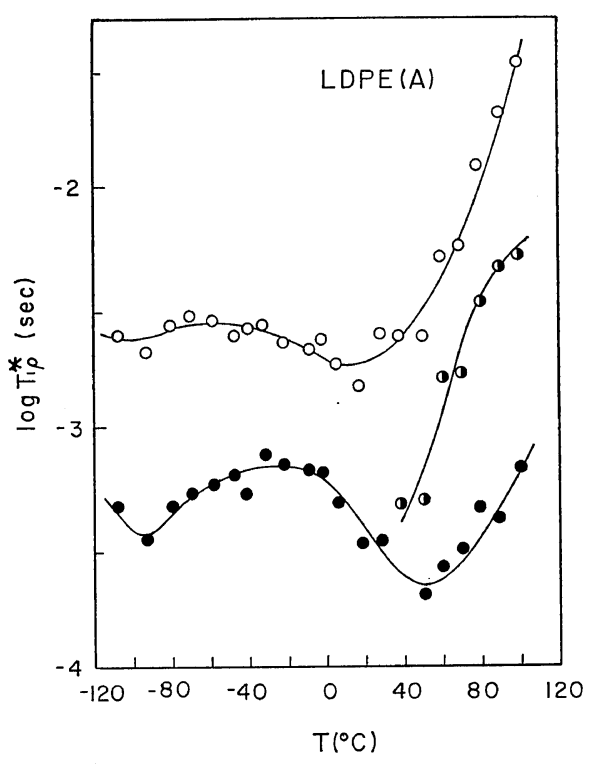

Figure 13. Temperature dependence of $T_{1 \rho}^{*}$ of the three phases in LDPE (A) obtained by solid echo train.

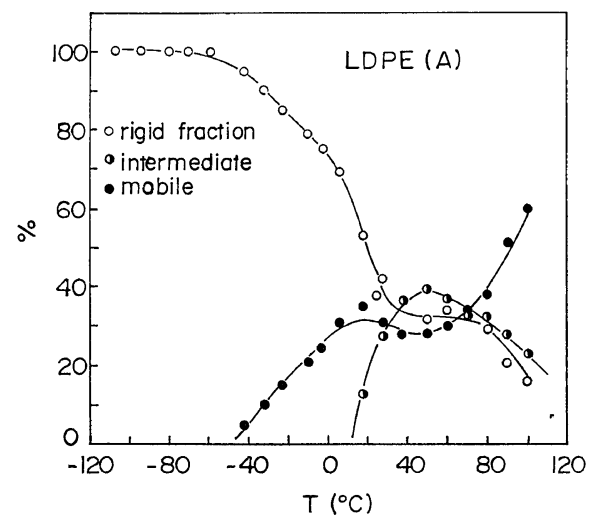

Figure 14. Temperature dependence of the quantity of the three phases obtained by solid echo.

component with the longest $T_{1 \rho}^{*}$ and it may be from the crystalline phase of the system. The component with the shortest $T_{1 \rho}^{*}$ may be from the amorphous phase of the system. Above about $40^{\circ} \mathrm{C}$ one can obtain the signal that can be regarded as that of the intermediate phase.

In the present stage, the physical meaning in molecular level of the intermediate phase of these crystalline polymers cannot be obtained only by pulsed NMR but it seems to be sure 
that the intermediate phase can exist when the degree of the molecular motion of the system is to a certain extent, i.e., the molecular motion in the amorphous phase of the system is the order of micro-Brownian one and yet the molecular motion in the crystalline phase of the system is not so active to melt the crystalline state of polymers. It can also be predicted that the intermediate phase may exist not only in polyethylene and Nylon 6 but also in almost all of the crystalline polymers. Moreover, the intermediate phase cannot probably be measured by other method as X-ray analysis since this phase seems to have no crystalline order as in crystalline state nor to be in perfect disorder as in amorphous state. The nature of the intermediate phase will be more precisely investigated by multiple-pulse NMR in near future.

\section{CONCLUSION}

It has been indicated that multiple-pulse NMR is quite useful to analyse heterogeneous polymer systems. In this paper, the problem originated from its principle or its detecting system of broad-line NMR or conventional pulsed NMR are pointed out and the distinguishability of several methods for analysing heterogeneous systems is calculated using a simple two phase model.

To solve those problems application of multiple-pulse techniques to these systems are proposed, i.e., the application of solid echo for $T_{2}$ which can measure the complete free induction decay without the influence of the system recovery time and the application of solid echo train for $T_{1 \rho}^{*}$ which can measure the $T_{1 \rho}^{*}$, s of the system at one time.

Both solid echo and solid echo train techniques are applied to many heterogeneous polymer systems. It has been confirmed that there exist three phases, namely crystalline, intermediate and amorphous phases in polyethylene and Nylon 6. Temperature dependence of the fraction, $T_{2}$ and $T_{1 \rho}^{*}$ of the three phases in low-density polyethylene is measured between -120 to $100^{\circ} \mathrm{C}$.

Acknowledgements. We would like to thank Professor T. Hashi at Kyoto University, Professor S. Fujiwara at the University of Tokyo and Professor R. Chûjô at Tokyo Institute of Technology for their valuable discussion. Messrs T. Takagi and T. Hashimoto of the Toyo Soda Industrial Company Ltd. kindly gave us several polyethylene samples. Mr. M. Tanaka of our (K. F. and T. N.) laboratory helped with the experiments.

\section{APPENDIX}

\section{Effect of Modulation on the Broad-Line NMR Spectra}

Broad-line NMR has some problems as eq $1-7$ when it is used to analyse heterogeneous systems. But more serious problems arise to obtain derivative curve of the NMR absorption curve, namely, the effect of modulation.

The effect of modulation on the derivative curve of the spectra has already been calculated by Smith and others ${ }^{5}$ as Figure 15, where $h_{m} /$ $\Delta H_{1 / 2}$ means the ratio of the modulation amplitude to the half width of the true absorption

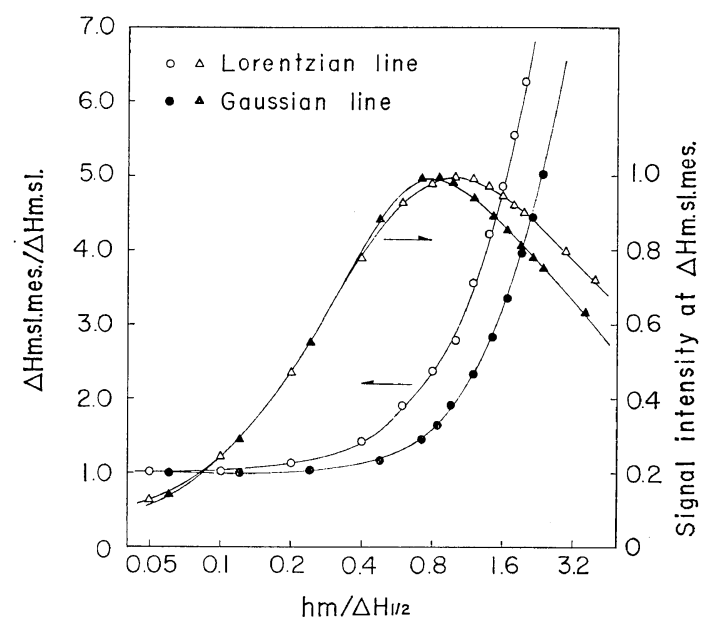

Figure 15. Effect of modulation on the derivative curve of the spectra calculated by Smith and others $^{5-7}$ for broad-line NMR.

spectra, $\Delta H_{\mathrm{m} . \mathrm{s} 1 . \mathrm{mes}} / \Delta H_{\mathrm{m} . \mathrm{s1}}$. means the ratio of the measured maximum slope width to that of the true absorption spectra, and the vertical axis of the right side of the figure indicates the signal intensity at the measured maximum slope width. The effect of modulation is indicated both in case of the original absorption line being 
Gaussian and Lorentzian.

From Figure 15 it is easily understood that in heterogeneous systems the derivative of the one phase which has the longer $T_{2}$ (i.e., narrower $\left.\Delta H_{1 / 2}\right)$ than other phases is always influenced in its signal intensity and its $\Delta H_{\mathrm{m} . \mathrm{s} 1 . \mathrm{mes}}$.

For example, in the case of LDPE (A), when the modulation amplitude $h_{\mathrm{m}}$ is arranged to the $1 / 5$ of the intermediate phase, the signal intensity of the crystalline phase decreases to $1 / 5$ of the normal value even though the $\Delta H_{1 / 2}$ of that phase gives correct value and, moreover, the signal intensity of the amorphous increases to twice of the normal value and the $\Delta H_{\text {m.si.mes. }}$ of that phase broadens to 2.5 of its original width. These situations always occur in measuring heterogeneous systems since one has to modulate to a certain degree to get derivatives in a high $S / N$ ratio for broad-line NMR.

\section{REFERENCES}

1. K. Bergmann and K. Nawotki, Kolloid-Z., 219, 132 (1967).

2. D. W. McCall, D. C. Douglass, and D. R. Falcone, J. Phys. Chem., 71, 998 (1967).

3. J. G. Powles and J. H. Strange, Proc. Phys. Soc. (London), 82, 6 (1963).

4. J. S. Waugh and C. H. Wang, Phys. Rev., 162, 209 (1967).

5. H. Wahlquist, J. Chem. Phys., 35, 1708 (1961).

6. G. W. Smith, J. Appl. Phys., 35, 1217 (1964).

7. H. A. Buckmaster, et al., ibid., 39, 4486 (1968).
8. D. W. McCall and D. C. Douglass, Polymer, 4, 93 (1963).

9. D. W. McCall and D. C. Douglass, ibid., 4, 433 (1963).

10. K. Fujimoto and T. Nishi, Nihon Gomu Kyokaishi (J. Soc. Rubber Ind. Japan), 43, 54 (1970).

11. K. Fujimoto and T. Nishi, ibid., 43, 465 (1970).

12. P. R. Swan, J. Polym. Sci., 56, 403 (1962).

13. I. Nitta and H. Tadokoro, Kobunshi (High Polymers, Japan), 5, 346 (1956).

14. B. Wunderlich, J. Polym. Sci., Part A-2, 5, 987 (1967).

15. M. Dole and B. Wunderlich, Makromol. Chem., 34, 29 (1959).

16. A. Abragam, "Principles of Nuclear Magnetism," Clarendon Press, Oxford, 1961.

17. R. Chujo, J. Phys. Soc. Japan, 18, 124 (1963).

18. H. Y. Carr and E. M. Purcell, Phys. Rev., 94, 630 (1954).

19. I. J. Lowe and R. E. Norberg, ibid., 107, 46 (1957).

20. K. Neki and M. Takayanagi, Rept. Progr. Polym. Phys. Japan, 8, 281 (1965).

21. B. Crist and A. Peterlin, J. Polym. Sci., Part $A-2,7,1165$ (1969).

22. D. H. Droste, A. T. DiBenedetto, and E. O. Stejskal, ibid., 9, 187 (1971).

23. R. Kubo, "Advances in Chemical Physics," XV, K. E. Schuler, Ed., Interscience Publishers, New York, N. Y., 1969, p 101.

24. D. C. Douglass and V. J. McBriety, J. Chem. Phys., 54, 4085 (1971).

25. H. G. Olf and A. Peterlin, Kolloid-Z., 215, 95 (1967). 